\title{
Research Briefs
}

\section{PALAEONTOLOGY}

\section{The earliest terrestrial animal in Gondwana}

Gondwanascorpio emzantsiensis is a new genus and species of scorpion from 360-million-year-old (Late Devonian) deposits near Grahamstown, Eastern Cape, South Africa, and has been described by Robert Gess from the University of the Witwatersrand. This finding adds to the sparse record of Late Devonian scorpion fauna and provides the first evidence of Palaeozoic scorpions from Gondwana. The find is also the first record of a scorpion occurring at high latitudes. G. emzantsiensis' close resemblance to contemporary taxa from Laurasia and China is consistent with evidence for increasingly uniform terrestrial ecosystems by the end of the Devonian period, characterised by cosmopolitan plant genera such as the progymnosperm tree Archaeopteris. This uniformity may in part reflect increasing proximity between Laurasia and Gondwana towards the end of the Devonian. The discovery of $G$. emzantsiensis also provides the earliest record of a terrestrial animal in Gondwana.

Gess RW. The earliest record of terrestrial animals in Gondwana: A scorpion from the Famennian (Late Devonian) Witpoort Formation of South Africa. African Invertebrates. 2013;54(2):373-379. http://africaninvertebrates.org/ojs/index.php/Al/article/view/284

\section{WILDLIFE BIOLOGY}

\section{Isotopes illuminate antelope diets}

Antelope diets have been studied through visual observation as well as through the analysis of stomach contents or faeces - methods which can be imprecise and messy. Now, a new approach, adopted by Djagoun and colleagues, involves the use of stable carbon isotopes in faeces to explore seasonal dietary preferences along the browser-grazer continuum. This method can be used to compare the diets of the same species in different habitats or between species in the same habitat, or to obtain continent-wide averages derived from field studies. Recent results show that oribi and reedbuck, assumed to be grazers, can become predominantly browsers under certain environmental and habitat conditions, while bushbuck, common duiker and red-flanked duiker may consume more grass than previously reported. The results also demonstrate temporal diet switches at monthly and seasonal scales, indicating that even supposed stenotopic grazers and browsers can have highly variable diets. Isotopes are now also being used to investigate the diets of elephants and suids in Africa.

Djagoun CAMS, Dodron D, Sealy J, Mensah GA, Sinsin B. Stable carbon isotope analysis of the diets of West African bovids in Pendjari Biosphere Reserve, Northern Benin. South African Journal of Wildlife Research. 2013;43(1):33-43

\section{EDUCATION}

\section{Help for children who struggle with early numeracy}

In an experimental study, Antje Ehlert and Annemarie Fritz of the University of Duisburg-Essen found that children with large deficits in mathematics can be supported successfully by means of a highly adaptive support measure - known as the MARKO-T programme - and that the effects of this support can be maintained. A total of 32 third-graders with learning difficulties received support while two other groups, each with 32 unimpaired first-graders, were paralleled according to their mathematical and cognitive achievements, respectively. The results showed that the very poor mathematical performance of the educationally impaired children could be improved significantly with this support programme. Even 4 months after the end of the training, significant support effects could still be established when compared with the educationally impaired control group. The comparison with the two control groups demonstrated that the developmental curve of the children with learning difficulties increased in a way that was comparable to that of the unimpaired first-graders.

Ehlert A, Fritz A. Evaluation of a maths training programme for children with learning difficulties. South African Journal of Childhood Education. 2013;3(1):117-149. http://www.uj.ac.za/EN/Faculties/edu/Centresandlnstitutes/UJICE/SouthAfricanJournalofChildhoodEducation/Pages/Onlineissues.aspx

\section{SCHOLARLY PUBLISHING}

\section{Scholarly communication}

Despite predictions that emerging technologies will transform how research is conducted, disseminated, and rewarded, why do we see so little actual shift in how scholars in the most competitive and aspirant institutions actually disseminate their research? Diane Harley of the Center for the Study of Higher Education at the University of California, Berkeley, describes research on faculty values and needs in scholarly communications that confirm a number of conservative tendencies in publishing. These tendencies, influenced by tenure and promotion requirements, as well as disciplinary cultures, have both positive and negative consequences. Rigorous research could inform development of good practices and policies in academic publishing, as well as counter rhetoric concerning the future of peer review and scholarly communication.

Harley D. Scholarly communication: Cultural contexts, evolving models. Science. 2013;342(6154):80-82. http://www.sciencemag.org/content/342/6154/80.full

HOW TO CITE: Research briefs. S Afr J Sci. 2013;109(11/12), Art. \#a0042, 1 page. http://dx.doi.org/10.1590/sajs.2013/a0042 